\title{
COMPUTER-SUPPORT TOOL TO OPTIMIZE BRIDGES AUTOMATICALLY
}

\author{
T. GARCÍA-SEGURA, V. YEPES \& J. ALCALÁ \\ Institute of Concrete Science and Technology (ICITECH), Universitat Politècnica de València, Spain.
}

\begin{abstract}
In bridge design, many variables like material grades, cross-sectional dimensions, passive and prestressing steel need to be modeled to evaluate structural performance. Efficiency gains are intended while satisfying the serviceability and ultimate limit states imposed by the structural code. In this paper, a computer-support tool is presented to analyze continuous post-tensioned concrete (PSC) box-girder road bridges, to minimize the cost as well as to provide optimum design variables. The program encompasses six modules to perform the optimization process, the finite-element analysis, and the limit states verification. The methodology is defined and applied to a case study. A harmony search (HS) algorithm optimizes 33 variables that define a three-span PSC box-girder bridge located in a coastal region. However, the same procedure could be implemented to optimize any structure. This tool enables one to define the fixed parameters and the variables that are optimized by the heuristic algorithm. Moreover, the output provides useful rules to guide engineers in designing PSC box-girder road bridges.

Keywords: box-girder bridges, computer-support tool, harmony search, post-tensioned concrete.
\end{abstract}

\section{INTRODUCTION}

Bridges are designed according to topographical and traffic conditions. It is essential to take landscape integration into consideration. Based on these specifications, the engineer should identify the best design. Optimization methods follow an intelligent process of structural analysis, constrain checking for a known design, and redesigning the process in which the design variables are modified with the aim of optimizing the objective function. Hare et al. [1] presented a review of heuristic algorithms employed in structural optimization. These methods, in contrast to mathematical programming optimizers, can be used to address complex and realistic structural optimization problems of discrete variables.

Among the heuristic algorithms, Genetic Algorithms (GAs), Memetic Algorithms (MAs), Simulated Annealing (SA), Ant Colony Optimization (ACO), Particle Swarm Optimization (PSO), Glowworm Swarm Optimization (GSO), Harmony Search (HS) and Tabu Search (TS), can be outlined. Hybrid fiber reinforced polymeric decks and cable-stayed bridges have been optimized using GAs [2]. MA was proposed to design road bridges with steel fiber reinforcement [3]. SA is a popular algorithm in structural optimization. This algorithm performs a local search with a jumping property, which ensures a good convergence. For this reason, SA has been hybridized with GA and GSO to design prestressed concrete precast road bridges [4-6] and reinforced concrete (RC) I-beams [7, 8]. Martínez et al. [9] optmized tall piers for railway bridge viaducts by ACO. Retaining walls examples were optimized by PSO [10] and SA [11]. PSO was also used to design steel space frames [12]. HS proved its efficiency in finding the best design of post-tensioned concrete box-girder bridges [13], and concrete columns [14].

This paper studies the best designs of PSC box-girder road bridges. This type of bridge is characterized by its low weight but good resistance to torsion, and both positive and negative bending moment. The use of this type of bridge has increased recently [15]. Despite there being guidelines regarding the geometry and amount of material $[16,17]$, these recommen- 
dations can be altered when other parameters are considered. Efficiency, in terms of maximum safety with minimum investment, is a common target. However, the great number of variables that can take a wide range of values makes it impossible to be addressed without artificial intelligence. In addition, accurate structural analysis by finite elements is a computationally intensive task.

This paper presents a computer-support tool, which performs a finite-element analysis and limit state verification while simultaneously carrying out a heuristic optimization. This methodology provides the best bridge design based on the fixed parameters and variables defined by the designer. The results show the optimal values of the design variables, including the material grades, cross-sectional dimensions and passive and post-tensioned reinforcement. The case study involves a three-span continuous PSC box-girder road bridge located in a coastal region.

\section{METHODOLOGY}

The methodology proposed is divided into six modules: heuristic algorithm, bridge design, CSiBridge input and analysis, CSiBridge output, limit state evaluation and criteria assessment. $\mathrm{CSiBridge}^{\odot}$ and $\mathrm{Matlab}^{\odot}$ are linked to carry out these steps. The modules are executed in the order that they are presented. This process is repeated until the termination criterion is reached. The methodology is applied to a three-span PSC box-girder bridge located in a coastal region.

\subsection{Heuristic algorithm}

The algorithm updates the design variables according to a strategy that combines some rules and randomness. Each heuristic is characterized by an efficient way to search for the optimal solution in the variable space. We use the HS algorithm. Geem et al. [18] proposed this algorithm as an analogy of the music improvisation process, in which the musicians improvise their instruments' pitch by searching for a perfect state of harmony.

The HS algorithm starts with a harmony memory matrix (HM) of random solutions, where its size is defined by the harmony memory size (HMS). The solutions are checked against the structural constraints, and they should be feasible to be stored in an HM. Then, new harmony vectors are improvised, based on the memory consideration, pitch adjustment, and random selection. Two parameters determine the probability of these three operators: the harmony memory considering rate (HMCR) and the pitch adjusting rate (PAR). The memory consideration, in which the value of the variable is randomly inherited from the values stored in the HM, has a probability of an HMCR. On the contrary, the value is assigned randomly for the permissible set. The random selection has a probability of (1-HMCR). The value can be subjected to a pitch adjustment with the probability of PAR. In this case, the value is modified one position up or down.

\subsection{Bridge design}

This module receives the new harmony vector and completes the design with the variable and parameter information. Once the values of the variables are determined, the complete design definition is straightforward. The selection of the variables and parameters is related to the designer's competence. In addition, we now evaluate the section properties required for the later limit state checking. 
The parameters chosen for the bridge problem are the span length and the width of the deck. The main and the external spans have a length of $44 \mathrm{~m}$ and $35.2 \mathrm{~m}$, respectively. The width is equal to $11.8 \mathrm{~m}$, to fit two $3.5 \mathrm{~m}$-wide lanes, $1 \mathrm{~m}$-wide inner verge, $2.5 \mathrm{~m}$-wide outer verge and two $0.65-\mathrm{m}$ parapet spaces. In this case, 33 variables are defined. Figure 1 shows the cross-section and the geometrical and reinforcing steel variables. The eight geometrical variables are: the depth $(h)$, the width of the bottom slab $(b)$, the width of the web inclination $(d)$, the thickness of the top slab $\left(e_{s}\right)$, the thickness of the external flange section $\left(e_{v}\right)$, the thickness of the internal flange section $\left(e_{v a}\right)$, the thickness of the bottom slab $\left(e_{i}\right)$, and the thickness of the webs $\left(e_{a}\right)$.

The concrete is defined by its strength $\left(f_{c k}\right)$. Regarding the post-tensioning steel, the parabolic layout is determined by the eccentricity in the external spans $\left(0.375 \cdot \mathrm{L}_{2}\right.$ from the abutments), the eccentricity over the piers, the eccentricity in the central span where the bending moment reaches its maximum, and the distance from the piers to the point of inflection. While the eccentricity in the central span and over the piers is fixed according to the allowed maximum, the variables are the eccentricity in the external span as a percentage of half the depth $\left(e_{p}\right)$, the point of inflection as a percentage of the main span length $\left(L_{p i}\right)$, and the number of strands $\left(N_{S}\right)$. The prestressing force is defined considering that each strand is prestressed to $195.52 \mathrm{kN}$.

The reinforcing steel is designed by 21 variables: the diameter of the longitudinal reinforcing steel $\left(L R_{1}, L R_{2}, L R_{3}, L R_{4}, L R_{5}, L R_{6}, L R_{7}, L R_{8}, L R_{9}, L R_{10}\right)$, the diameter of the transverse reinforcement $\left(T R_{1}, T R_{2}, T R_{3}, T R_{4}, T R_{4}, T R_{5}, T R_{6}, T R_{7}, T R_{8}\right)$, the number of bars $\left(N_{L R}\right)$ per meter and the spacing of all the transverse reinforcing $\left(\mathrm{S}_{\mathrm{TR}}\right)$. Note that $L R_{7}$ and $L R_{8}$ are the extra reinforcements in the top slab covering the pier zone (L/5 on both sides of the piers) and the remainder of the span. Likewise, $L R_{9}$ and $L R_{10}$ cover the same zones but in the bottom slab. Regarding the extra transverse reinforcement, $T R_{4}$, is placed at the same position as $T R_{4}$ and covers the support zone, $T R_{8}$ is the extra reinforcement over the flanges. $T R_{9}$ is fixed as $12 \mathrm{~mm}$.

Other geometrical dimensions, like $t_{1}, t_{2}, t_{3}$ and $t_{4}$ are obtained from the values of other variables eqns (1)-(4).

$$
\begin{gathered}
t_{1}=e_{v a}-e_{s} \\
t_{2}=\frac{b+2 * d}{5} \\
t_{3}=e_{i} \\
t_{4}=\frac{b}{10}
\end{gathered}
$$

\section{3 $\mathrm{CSiBridge}^{\odot}$ input and analysis}

The bridge design is transferred to the software that analyzes the structure. In this case, CSiBridge $^{\odot}$ is used to perform the structural analysis. This program has an Open Application Programming Interface (OAPI) to allow other software to be integrated with CSiBridge ${ }^{\odot}$. 


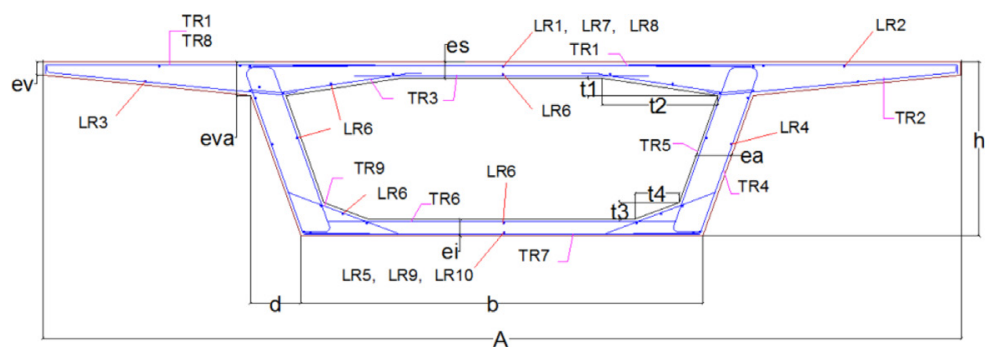

Figure 1: PSC box-girder bridge cross-section. Geometrical and reinforcing steel variables.

First, Matlab starts the CSiBridge ${ }^{\odot}$ application. Then, the model can be created by importing a file with the bridge information or by creating it through the OAPI. In this case, a \$br document with the structure information is imported. This document is updated with each iteration. The design changes affected by the new values of the variables are modified in the document. Then, the model is analyzed through CSiBridge ${ }^{\odot}$.

The $\$$ br document also contains the actions. These are the deck self-weight, the parapet $(1 \mathrm{kN} / \mathrm{m})$ and asphalt $\left(24 \mathrm{kN} / \mathrm{m}^{3}\right)$ load, the post-tensioned steel effect, the traffic loads and thermal gradient defined by the IAP-11 code [19], and the differential settling in each support (i.e. $5 \mathrm{~mm}$ ). Regarding the model, shell elements are used for the box-girder. A reinforcement grid is embedded in the shell element. This is defined according to the reinforcing steel variables. The post-tensioning steel is incorporated in the model through tendons. Likewise, the parabolic layout and the prestressing force depend on the current variable information.

\section{4 $\mathrm{CSiBridge}^{\odot}$ output}

The results of $\mathrm{CSiBridge}^{\odot}$ are extracted employing OAPI functions. At first, the shell and point information is obtained. Then, OAPI functions report the area forces and stresses for a specified area element. These results can be taken for each combination of loads. There are OAPI functions to obtain the longitudinal stresses for each combination at a single stress point in a superstructure section cut. The joint displacements for the specified points are also obtained to calculate the bridge deflection.

\subsection{Limit state evaluation}

This section evaluates the bridge resistance. In addition, knowing the load effects of the previous section, the limit states are checked. This study follows the Spanish code [19, 20], based on the Eurocode [21, 22]. The ultimate limit states of shear, flexure, torsion, and shear between web and flanges are verified. Regarding the serviceability limit state, the instantaneous and time-dependent deflection with respect to the precamber has to be smaller than $1 / 1400$ of the main span length for the characteristic combination [20]; the frequent value for the live loads is restricted to $1 / 1000$ of the main span length [19]. To guarantee the durability conditions in a coastal environment, a concrete cover of $65 \mathrm{~mm}$ is demanded. The fibers located $100 \mathrm{~mm}$ above and below the strands cannot be in a decompression state. Feasible solutions continue to the next module. Otherwise, the procedure returns to module 1 , and a new solution is generated. 


\subsection{Criteria assessment}

We consider the cost as an optimization criterion. However, any other criterion can be evaluated in this section. The total cost is assessed as the sum of the concrete, the post-tensioning steel, the reinforcing steel, and the formwork. The cost of each component is obtained as the product of the unit cost and the measurement. The unit costs are summarized in Table 1. These values are obtained from the BEDEC database of the Institute of Construction Technology of Catalonia [23]. García-Segura et al. [13] explained these prices in detail. The volume of concrete, the amount of post-tensioning steel, the amount of reinforcing steel and the area of the formwork are obtained as the measurements.

If the cost of the new solution is better than the worst harmony solution stored in HM, then the worst harmony vector is replaced by the new vector. Otherwise, this new vector is ignored. The process continues from module 1 to 6 until 200 sequential improvisations without improvement are reached.

\section{RESULTS}

The calibration of HS recommended HMS $=50, \mathrm{HMCR}=0.7$ and PAR $=0.4$. The best solution is summarized in Table 2. The cost of the concrete, the post-tensioning steel, the reinforcing steel and the formwork, is $405099.22 €$. The cross-section has a depth of $2.3 \mathrm{~m}$. Therefore, the ratio between the main span length and the depth is 19.1. Given a web inclination width of $0.45 \mathrm{~m}$ and a thickness of the internal flange section of $0.4 \mathrm{~m}$, the web slope is equal to 4.2 . The width of the bottom slab is $4.45 \mathrm{~m}$. This corresponds to a ratio of 0.38 of the deck width. The thickness of the top slab and that of the external flange is $0.25 \mathrm{~m}$. However, the thickness of the bottom slab adopts a value of $0.3 \mathrm{~m}$ to increase the flexure capacity over the supports. The thickness of the webs is $0.6 \mathrm{~m}$. Regarding the concrete strength, $35 \mathrm{MPa}$ concrete is used. This indicates that it is not economic to increase the concrete strength.

Table 1: Unit prices.

\begin{tabular}{lr}
\hline Unit measurements & Cost $(€)$ \\
\hline $\mathrm{m}^{3}$ of concrete HP-35 & 104.57 \\
$\mathrm{~m}^{3}$ of concrete HP-40 & 109.33 \\
$\mathrm{~m}^{3}$ of concrete HP-45 & 114.10 \\
$\mathrm{~m}^{3}$ of concrete HP-50 & 118.87 \\
$\mathrm{~m}^{3}$ of concrete HP-55 & 123.64 \\
$\mathrm{~m}^{3}$ of concrete HP-60 & 128.41 \\
$\mathrm{~m}^{3}$ of concrete HP-70 & 137.95 \\
$\mathrm{~m}^{3}$ of concrete HP-80 & 147.49 \\
$\mathrm{~m}^{3}$ of concrete HP-90 & 157.02 \\
$\mathrm{~m}^{3}$ of concrete HP-100 & 166.56 \\
$\mathrm{~kg}$ of reinforcing steel (B-500-S) & 1.16 \\
$\mathrm{~kg}$ of prestressing steel (Y1860-S7) & 3.40 \\
$\mathrm{~m}^{2}$ of formwork & 33.81 \\
\hline
\end{tabular}


Table 2: Best bridge solution.

\begin{tabular}{lr}
\hline & Result values \\
\hline Cost $(€)$ & 405099.22 \\
$h(\mathrm{~m})$ & 2.30 \\
$d(\mathrm{~m})$ & 0.45 \\
$b(\mathrm{~m})$ & 4.45 \\
$e_{s}(\mathrm{~m})$ & 0.25 \\
$e_{v}(\mathrm{~m})$ & 0.25 \\
$e_{i}(\mathrm{~m})$ & 0.35 \\
$e_{a}(\mathrm{~m})$ & 0.60 \\
$e_{v a}(\mathrm{~m})$ & 0.40 \\
$f_{c k}(\mathrm{MPa})$ & 35.00 \\
$\mathrm{~L}_{\mathrm{pi}}$ & 0.10 \\
$\mathrm{e}_{\mathrm{p}}$ & 0.50 \\
Prestressing steel $(\mathrm{kg})$ & 29676.21 \\
Reinforcing steel $(\mathrm{kg})$ & 90294.37 \\
Concrete $\left(\mathrm{m}^{3}\right)$ & 909.47 \\
\hline
\end{tabular}

The layout of the post-tensioned steel is determined by the distance from the piers to the point of inflection, which is established as 0.1 times the span length, and the eccentricity in the external spans, which is set to a quarter of the depth. Moreover, the amount of posttensioned steel is equal to $29676.21 \mathrm{~kg}$. The amount of reinforcement reaches $90294.37 \mathrm{~kg}$. A concrete volume of $909.47 \mathrm{~m}^{3}$ is required.

\section{CONCLUSIONS}

We have proposed a computer-support tool for the automatic optimization of bridges. Six modules are embedded within the proposed methodology. The heuristic algorithm module updates the design variables to search effectively for the optimal solution. The HS algorithm is used for this task. The bridge design module completes the design from the current variable vector and the parameter information. This module also evaluates the section properties, which are used later in the limit state checking. Then, the design is transferred to CSiBridge ${ }^{\odot}$, which carries out the analysis. To this end, a \$br document is updated with the structure information. This document is imported by $\mathrm{CSiBridge}^{\odot}$ and the model is run. The next module extracts the structural response through OAPI functions. This is used in the subsequent module to check the limit states. Finally, the criteria assessment module evaluates the objective selected for the optimization process. This methodology is applied to a three-span continuous PSC box-girder road bridge located in a coastal region. The best design according to the parameters selected is presented.

\section{ACKNOWLEDGMENTS}

The authors acknowledge the financial support of the Spanish Ministry of Economy and Competitiveness, along with FEDER funding (BRIDLIFE Project: BIA2014-56574-R) and the Research and Development Support Program of Universitat Politècnica de València (PAID-02-15). 


\section{REFERENCES}

[1] Hare, W., Nutini, J. \& Tesfamariam S., A survey of non-gradient optimization methods in structural engineering. Advances in Engineering Software, 59, pp. 19-28, 2013. http://dx.doi.org/10.1016/j.advengsoft.2013.03.001

[2] Cai, H. \& Aref, A.J., A genetic algorithm-based multi-objective optimization for hybrid fiber reinforced polymeric deck and cable system of cable-stayed bridges. Structural and Multidisciplinary Optimization, 52(3), pp. 583-594, 2015. http://dx.doi.org/10.1007/s00158-015-1266-4

[3] Martí, J.V., Yepes, V. \& González-Vidosa, F., Memetic algorithm approach to designing precast-prestressed concrete road bridges with steel fiber reinforcement. Journal of Structural Engineering, 141(2), 04014114, 2015. http://dx.doi.org/10.1061/(ASCE)ST.1943-541X.0001058

[4] Martí, J.V., González-Vidosa, F., Yepes, V. \& Alcalá, J., Design of prestressed concrete precast road bridges with hybrid simulated annealing. Engineering Structures, $\mathbf{4 8}$, pp. 342-352, 2013. http://dx.doi.org/10.1016/j.engstruct.2012.09.014

[5] Martí, J.V., García-Segura, T. \& Yepes, V., Structural design of precast-prestressed concrete U-beam road bridges based on embodied energy. Journal of Cleaner Production, 120, pp. 231-240, 2016. http://dx.doi.org/10.1016/j.jclepro.2016.02.024

[6] Yepes, V., Martí, J.V. \& García-Segura, T., Cost and $\mathrm{CO}_{2}$ emission optimization of precast-prestressed concrete U-beam road bridges by a hybrid glowworm swarm algorithm. Automation in Construction, 49, pp. 123-134, 2015. http://dx.doi.org/10.1016/j.autcon.2014.10.013

[7] Yepes, V., García-Segura, T. \& Moreno-Jiménez, J.M., A cognitive approach for the multi-objective optimization of RC structural problems. Archives of Civil and Mechanical Engineering, 15(4), pp. 1024-1036, 2015. http://dx.doi.org/10.1016/j.acme.2015.05.001

[8] García-Segura, T., Yepes, V., Martí, J.V. \& Alcalá, J., Optimization of concrete I-beams using a new hybrid glowworm swarm algorithm. Latin American Journal of Solids and Structures, 11(7), pp. 1190-1205, 2014. http://dx.doi.org/10.1590/S1679-78252014000700007

[9] Martinez, F.J., Gonzalez-Vidosa, F., Hospitaler, A. \& Alcala, J., Design of tall bridge piers by ant colony optimization. Engineering Structures, 33(8), pp. 2320-2329, 2011. http://dx.doi.org/10.1016/j.engstruct.2011.04.005

[10] Gandomi, A.H., Kashani, A.R., Roke, D.A. \& Mousavi, M., Optimization of retaining wall design using recent swarm intelligence techniques. Engineering Structures, 103, pp. 72-84, 2015. http://dx.doi.org/10.1016/j.engstruct.2015.08.034

[11] Yepes, V., Alcala, J., Perea, C. \& González-Vidosa, F., A parametric study of optimum earth-retaining walls by simulated annealing. Engineering Structures, 30(3), pp. 821-830, 2008. http://dx.doi.org/10.1016/j.engstruct.2007.05.023

[12] Degertekin, S.O., Saka, M.P. \& Hayalioglu, M.S., Optimal load and resistance factor design of geometrically nonlinear steel space frames via tabu search and genetic algorithm. Engineering Structures, 30(1), pp. 197-205, 2008. http://dx.doi.org/10.1016/j.engstruct.2007.03.014 
[13] García-Segura, T., Yepes, V., Alcalá, J. \& Pérez-López, E., Hybrid harmony search for sustainable design of post-tensioned concrete box-girder pedestrian bridges. Engineering Structures, 92, pp. 112-122, 2015.

http://dx.doi.org/10.1016/j.engstruct.2015.03.015

[14] de Medeiros, G.F. \& Kripka, M., Optimization of reinforced concrete columns according to different environmental impact assessment parameters. Engineering Structures, 59, pp. 185-194, 2014.

http://dx.doi.org/10.1016/j.engstruct.2013.10.045

[15] Ates, S., Numerical modelling of continuous concrete box girder bridges considering construction stages. Applied Mathematical Modelling, 35(8), pp. 3809-3820, 2011. http://dx.doi.org/10.1016/j.apm.2011.02.016

[16] Schlaich, J. \& Scheef, H., Concrete Box-Girder Bridges, International Association for Bridge and Structural Engineering. Zürich, Switzerland, 1982.

[17] Fomento, M., New Overpasses: General Concepts, Ministerio de Fomento, Madrid, Spain, 2000 (in Spanish).

[18] Geem, Z.W., Kim, J.H. \& Loganathan, G.V., A new heuristic optimization algorithm: harmony search. Simulation, 76(2), pp. 60-68, 2001. http://dx.doi.org/10.1177/003754970107600201

[19] Fomento, M., IAP-11: Code on the Actions for the Design of Road Bridges, Ministerio de Fomento, Madrid, Spain, 2011 (in Spanish).

[20] Fomento, M., EHE-08: Code on structural concrete, Ministerio de Fomento, Madrid, Spain, 2008 (in Spanish).

[21] European Committee for Standardisation., EN1992-2:2005. Eurocode 2: Design of Concrete Structures- Part 2: Concrete Bridge-Design and Detailing Rules, Brussels, 2005.

[22] European Committee for Standardisation., EN 1991-2:2002. Eurocode 1: Actions on Structures-Part 2: Traffic Loads Bridges, Brussels, 2002.

[23] BEDEC. Institute of Construction Technology of Catalonia. Barcelona, Spain, available at: www.itec.cat 